University of Wollongong

Research Online

Faculty of Engineering - Papers (Archive)

Faculty of Engineering and Information

Sciences

$1-1-2011$

\title{
Removal of carbamazepine and sulfamethoxazole by MBR under anoxic and aerobic conditions
}

\author{
Faisal I. Hai \\ University of Wollongong, faisal@uow.edu.au \\ Xueqing Li \\ University of Wollongong, xq1895@uow.edu.au \\ William E. Price \\ University of Wollongong, wprice@uow.edu.au \\ Long Nghiem \\ University of Wollongong, longn@uow.edu.au
}

Follow this and additional works at: https://ro.uow.edu.au/engpapers

Part of the Engineering Commons

https://ro.uow.edu.au/engpapers/2707

\section{Recommended Citation}

Hai, Faisal I.; Li, Xueqing; Price, William E.; and Nghiem, Long: Removal of carbamazepine and sulfamethoxazole by MBR under anoxic and aerobic conditions 2011, 10386-10390.

https://ro.uow.edu.au/engpapers/2707

Research Online is the open access institutional repository for the University of Wollongong. For further information contact the UOW Library: research-pubs@uow.edu.au 


\title{
Removal of carbamazepine and sulfamethoxazole by MBR under anoxic and aerobic conditions
}

\author{
Faisal I. Hai ${ }^{1}$, Xueqing $\mathrm{Li}^{1}$, William E. Price ${ }^{2}$, and Long D. Nghiem ${ }^{1, *}$ \\ ${ }^{1}$ Strategic Water Infrastructure Laboratory \\ School of Civil Mining and Environmental Engineering \\ The University of Wollongong, NSW 2522, Australia \\ ${ }^{2}$ Strategic Water Infrastructure Laboratory \\ School of Chemistry \\ The University of Wollongong, NSW 2522, Australia \\ * Corresponding author: Long Duc Nghiem, Email: longn@uow.edu.au; Ph +61 242214590
}

\begin{abstract}
This study reveals for the first time that near-anoxic conditions (dissolved oxygen, $\mathrm{DO}=0.5$ $\mathrm{mg} / \mathrm{L}$ ) can be a favourable operating regime for the removal of the persistent micropollutant carbamazepine by MBR treatment. The removal efficiencies of carbamazepine and sulfamethoxazole by an MBR were systematically examined and compared under near-anoxic (DO $=0.5 \mathrm{mg} / \mathrm{L})$ and aerobic $(\mathrm{DO}>2 \mathrm{mg} / \mathrm{L})$ conditions. Preliminary batch tests confirmed that sulfamethoxazole is amenable to both aerobic and anoxic biotransformation. However, carbamazepine - a known persistent compound - showed degradation only under an anoxic environment. In good agreement with the batch tests, during near-anoxic operation, under a high loading of $750 \mu \mathrm{g} / \mathrm{L} . \mathrm{d}$, an exceptionally high removal (68 $\pm 10 \%)$ of carbamazepine was achieved. In contrast, low removal efficiency $(12 \pm 11 \%)$ of carbamazepine was observed during operation under aerobic conditions. On the other hand, an average removal efficiency of $65 \%$ of sulfamethoxazole was achieved irrespective of the DO concentrations.

Keywords: anoxic; carbamazepine; dissolved oxygen (DO); membrane bioreactor (MBR); micropollutant.
\end{abstract}




\section{Introduction}

Wastewater-derived micropollutants including pharmaceutically active compounds are of significant concern due to their potential adverse human health and ecological effects (Virkutyte et al., 2010). Some of these micropollutants are not completely removed during conventional activated sludge treatment (CAS). Thus, sewage treatment plant effluents are important sources responsible for occurrence of many micropollutants in downstream water bodies. Compared to CAS, membrane bioreactors (MBR) can achieve better effluent quality regarding basic water quality parameters such as total organic carbon (TOC) and total nitrogen (TN) (Visvanathan et al., 2000). However, the superiority of MBR over CAS in the case of poorly biodegradable micropollutants remains uncertain (Bernhard et al., 2006; Clara et al., 2005; Weiss and Reemtsma, 2008).

Given the inherent advantages of MBR, namely, stable removal in a compact reactor and better resilience to shock-loading (Clara et al., 2005), there is significant scope for fine tuning the operational parameters and thus enhancing the performance of MBR for the removal of poorly biodegradable micropollutants. In the quest to enhance micropollutant removal, to date the effects of operational parameters such as HRT, SRT, $\mathrm{pH}$ and temperature on the removal efficiency of micropollutants by MBR treatment have been extensively studied (Cirja et al., 2008). However, as a notable omission, little is known about the effects of dissolved oxygen (DO) concentration on the removal of micropollutants by MBR treatment. An anoxic environment has been found to promote removal of certain groups of refractory compounds such as dyes (Hai et al., 2011). However, to date only a few studies have reported the suitability of anoxic conditions for micropollutant removal (Stasinakis et al., 2009; Zwiener and Frimmel, 2003).

Carbamazepine, which is an anti-epileptic drug, is composed of two benzene rings fused to an azepine group, which in turn is connected to an amide group. It is ubiquitously present in municipal wastewater and, due to its chemical stability, it is not significantly removed during conventional biological treatment (Zhang et al., 2008). To date both laboratory scale and pilot scale MBR plant studies have reported negligible to moderate removal (usually less than 10\%) of carbamazepine 
(Bernhard et al., 2006; Bo et al., 2009; Clara et al., 2005; Laera et al., 2011; Tadkaew et al., 2011; Weiss and Reemtsma, 2008). A comprehensive literature review conducted by the authors revealed the absence of any clear consensus about the effect of anoxic conditions on carbamazepine removal in MBR. For instance, negligible level of removal of carbamazepine was reported by Clara et al. (2005) and Abegglen et al. (2009), although different configurations of MBR (sequential anoxicaerobic MBR and aerobic MBR, respectively) were utilized in those studies. However, a few recent studies have reported better removal of carbamazepine under anoxic conditions during treatment in constructed wetland (Park et al., 2009) and river bank filtration (Maeng et al., 2011). It is also interesting to note that carbazole, which is a precursor, and acridine, which is a degradation product of carbamazepine, have been reported to be well degraded under anaerobic conditions (Kaiser et al., 1996; Tan and Ji, 2010). In addition, information regarding the anaerobic degradation of aromatic amides (Dipeolu et al., 2005) or heterocyclic nitrogenous compounds having building blocks similar to the azepine group (e.g., pyridine, pyrazine, indole) (Kaiser et al., 1996) can be found in the literature. The anoxic degradation potential of carabamazepine in MBR, therefore, needs to be further systematically studied.

In line with the background and important knowledge gaps outlined above, in this study, the removal of bulk organics and two selected pharmaceuticals (carabamazepine and sulfamethoxzole), by an MBR operated continuously in a very low DO environment was compared to that during the usual operation mode under aerobic conditions. Sulfamethoxazole is a readily biodegradable compound (Clara et al., 2005; Tadkaew et al., 2011) and it was included in the wastewater as a reference compound to judge the performance and stability of the bioreactor. Data from parallel batch tests were furnished to further elucidate the observations regarding the MBR performance. The potential difference in MBR performance under 'continuous very low DO operation', as applied in the current study, and the usual 'sequential anoxic-aerobic operation' was highlighted. This appears to be the first study to assess specifically the effect of DO levels on selected micropollutant removal. 


\section{Experimental}

\subsection{Model micropollutants and synthetic wastewater}

Analytical grade sulfamethoxazole and carbamazepine were purchased from Sigma-Aldrich (Saint Louis, MO, USA). Relevant chemical properties of these compounds are presented in Supplementary Data Table S1. Stock solutions were prepared at a concentration of $1 \mathrm{~g} / \mathrm{L}$ in pure methanol, stored at $-18{ }^{\circ} \mathrm{C}$ and used within one month. A synthetic wastewater described in a previous study (Tadkaew et al., 2011) was used. Although the studied micropollutants can only be found in municipal wastewater in the range from a few $\mathrm{ng} / \mathrm{L}$ to tens of $\mu \mathrm{g} / \mathrm{L}$, in this study to confirm the capacity of the MBR the concentration of each in the wastewater was kept at a rather high level $(750 \mu \mathrm{g} / \mathrm{L})$.

\subsection{Design and operating conditions of $M B R$}

A 14 L laboratory scale MBR system (Supplementary Data Figure S2) was used in this study. The reactor was seeded with activated sludge from another laboratory scale MBR system which had been in continuous operation for over 3 years (Tadkaew et al., 2011). It is well established that a DO concentration below $0.5 \mathrm{mg} / \mathrm{L}$ can be considered as an anoxic regime (Xing et al., 2006). On the other hand, by default, most MBR plants maintain a DO level of $2 \mathrm{mg} / \mathrm{L}$ or higher to ensure completely aerobic conditions (Wang et al., 2007). Therefore, in this study the DO concentration in the reactor was maintained at $0.5 \mathrm{mg} / \mathrm{L}$ and above $2 \mathrm{mg} / \mathrm{L}$ to establish near-anoxic and aerobic environments, respectively. This was done by monitoring the DO level in the reactor and accordingly controlling the intensity of air-supply through the diffusers. The MBR system was operated continuously at a hydraulic retention time of 24 hours first under near-anoxic conditions for 50 days and then under aerobic conditions for 30 days. The bioreactor temperature was controlled at $22 \pm 2{ }^{\circ} \mathrm{C}$. The mixed liquor $\mathrm{pH}$ remained stable around $7.8 \pm 0.1$ throughout the operating period, while the mixed liquor suspended solids (MLSS) concentration remained stable at 
$10.5 \pm 1 \mathrm{~g} / \mathrm{L}$ beyond day 25 . No sludge was withdrawn from the MBR except for the MLSS concentration measurement.

\subsection{Batch degradation tests}

A series of batch tests was conducted to ascertain the extent of abiotic and biotic degradation and adsorption both under anoxic and aerobic conditions. Sludge samples taken from MBR were centrifuged (Allegra X-12R, Beckman Coulter, USA) at $3270 \mathrm{~g}$ and washed with MilliQ water twice to minimize the amount of residual micropollutant. The centrifuged sludge was finally reconstituted with previously autoclaved synthetic wastewater (section 2.1) to obtain an initial MLSS concentration of $10 \mathrm{~g} / \mathrm{L}$. The target micropollutants were added to the mixed liquor to give a concentration of $750 \mu \mathrm{g} / \mathrm{Lof}$ each. Amber glass bottles $(100 \mathrm{~mL})$ were each completely filled with the mixed liquor such that the liquor overflowed. The bottles were then purged with high purity nitrogen gas, sealed with parafilm and plastic screw cap and then incubated for over two days at $25{ }^{\circ} \mathrm{C}$ and $150 \mathrm{rpm}$ in a temperature controlled rotary shaker (BL 4500, Bioline, Edward Instrument Company, NSW, Australia). All batch experiments were carried out in triplicate. Batch tests to simulate aerobic conditions were also conducted with the same protocol except that the sample bottles were not filled to overflowing and they were loosely covered with aluminum foil to facilitate intrusion of air. Control batch tests with autoclaved sludge were conducted to quantify adsorption of the micropollutants to the sludge. Test solutions containing only micropollutants in Milli-Q water were incubated to assess the removal efficiency in absence of alternate easily degradable substrate. Finally, the autoclaved synthetic wastewater containing the micropollutants but without any sludge was incubated to detect any potential abiotic adsorption/degradation.

\subsection{Analytical methods}

A Shimadzu HPLC system (Shimadzu, Kyoto, Japan) equipped with a Supelco Drug Discovery C18 column (with diameter, length and pore size of $4.6 \mathrm{~mm}, 150 \mathrm{~mm}$, and $5 \mu \mathrm{m}$, respectively) and a UV-Vis detector was used to measure the concentrations of the micropollutants in the feed and permeate (Li et al., 2011). The detection wavelength and column temperature were set at $280 \mathrm{~nm}$ 
and $20^{\circ} \mathrm{C}$, respectively. A sample injection volume of $50 \mu \mathrm{L}$ was used. The mobile phase composed

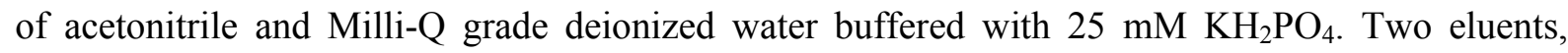
namely, eluent A (80\% acetonitrile $+20 \%$ buffer, v/v) and eluent B (20\% acetonitrile $+80 \%$ buffer, v/v) were delivered at $1.0 \mathrm{~mL} / \mathrm{min}$ through the column in time-dependent gradient proportions for 20 minutes. The proportion of eluent B remained at $100 \%$ for the first five minutes, then gradually dropped to $40 \%$ within the subsequent three minutes, remained at $40 \%$ for the next two minutes, sharply returned to $100 \%$ within the following one minute, and remained constant for the rest of the period. The retention time of sulfamethoxazole and carbamazepine were 8 and 12 minutes, respectively. Calibration always yielded standard curves with coefficients of determination $\left(\mathrm{R}^{2}\right)$ greater than 0.98 within the range of experimental concentrations used. The quantification limit for the analytes under investigation using these conditions was approximately $10 \mu \mathrm{g} / \mathrm{L}$.

Total organic carbon (TOC) and total nitrogen (TN) were analyzed using a Shimadzu

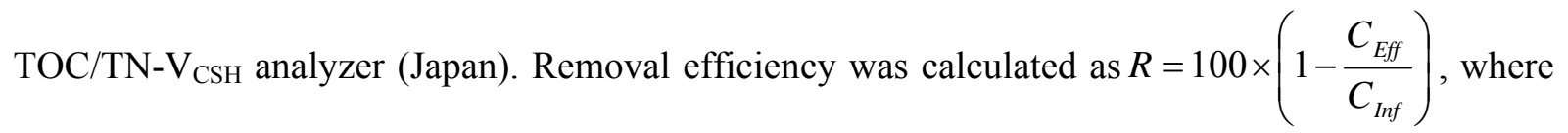
$\mathrm{C}_{\mathrm{Eff}}$ and $\mathrm{C}_{\text {Inf }}$ are effluent (or permeate) and influent concentrations $(\mu \mathrm{g} / \mathrm{L}$ ), respectively. It is noteworthy that the term removal here does not necessarily indicate complete mineralization of the trace organics to carbon dioxide and water. A spectrophotometer (UV 1700, Shimadzu, Japan) was used to measure the diminution of UV absorbance after MBR treatment. MLSS concentration in the reactor was measured according to the Standard Methods for the Examination of Water and Wastewater (Eaton et al., 2005).

\section{Results and discussion}

\subsection{Batch degradation test under anoxic and aerobic conditions}

The degradation of sulfamethoxazole and carbamazepine under both anoxic and aerobic conditions was investigated in a series of batch tests. The contribution of abiotic adsorption/degradation or adsorption onto sludge to the overall removal of both compounds was negligible (data not shown). Biodegradation of carbamazepine was only detected under anoxic 
conditions, while the biodegradation of sulfamethoxazole occurred under both anoxic and aerobic conditions (Figure 1). Previous reports have advocated the suitability of anoxic or anaerobic environments for micropollutant removal. For instance, Stasinakis et al. (2009) reported better removal of diuron during batch tests under anoxic environment $(>95 \%)$ in comparison to that in aerobic condition $(60 \%)$. However, to date the possible beneficial effects of the anoxic condition on the removal of sulfamethoxazole or carbamazepine have not been studied. As an additional aspect revealed by these batch tests, the presence of alternate substrate appear to strongly influence the degradation of the selected micropollutants. For both sulfamethoxazole and carbamazepine, faster degradation was observed when the test solution contained only the micropollutants. This is consistent with a recent study by Reungoat et al. (2010) who attributed insignificant micropollutant removal in the denitrification zone of a multi-barrier water reclamation plant to the preferential use of the added methanol as the primary electron donor by the bacteria.

\section{[FIGURE 1]}

\section{2. $M B R$ performance regarding basic water quality}

The average TOC and TN removal efficiency during operation under a DO concentration of $0.5 \mathrm{mg} / \mathrm{L}$ (up to day 45 ) was $97 \%$ and $94 \%$, respectively (Figure 2). Only a slight improvement of the TOC/TN removal was observed during the operation under aerobic conditions. It is noted that as compared to usual municipal wastewater the synthetic wastewater in use had a significantly higher carbon to nitrogen ratio $(\sim 20)$. Therefore, the high $\mathrm{TN}$ removal irrespective of the DO concentration could possibly be attributed to the conversion of dissolved organic nitrogen to biomass, which would then be retained by the membrane. The removal efficiency observed during the near-anoxic $(\mathrm{DO}=0.5 \mathrm{mg} / \mathrm{L})$ operation in our study was certainly higher than the observed typical moderate removals in anoxic compartment of an integrated anoxic-aerobic MBR (Chu et al., 2005). When this observation is taken into account in conjunction with the fact that similar TOC/TN removal efficiency was achieved during near-anoxic $(\mathrm{DO}=0.5 \mathrm{mg} / \mathrm{L})$ and aerobic $(\mathrm{DO}>2 \mathrm{mg} / \mathrm{L})$ operation, it may be inferred that a near-anoxic MBR can be applied to minimize the aeration cost pertaining 
to supply of dissolved oxygen to microbes without compromising the treatment performance. However, long-term membrane fouling potential under such treatment regime will need to be considered and this particular aspect is beyond the scope of the current study.

Of further interest in the context of the current study is the fact that similar to TOC/TN, no significant difference was observed in the MBR performance in terms of MLSS concentration, turbidity and UV absorbance during operations under near-anoxic and aerobic conditions (data not shown).

\subsection{Micropollutant removal}

Depending on the physicochemical properties, both biodegradation and adsorption can contribute to overall removal of micropollutants by MBR (Cirja et al., 2008). In a previous study (Li et al., 2011) negligible adsorption of the two studied compounds (carbamazepine and sulfamethoxazole) onto MBR sludge was demonstrated. In this study, in good agreement with the preliminary batch tests, a dramatic effect of operating DO on the removal efficiency of carbamazepine by the MBR was observed, while sulfamethoxazole removal was rather stable irrespective of the DO concentrations (Figure 2).

\section{[FIGURE 3]}

\subsubsection{Removal during near-anoxic ( $D O=0.5 \mathrm{mg} / \mathrm{L})$ operation}

Owing to the presence of an amide group in its structure, carbamazepine has been widely reported as an extremely recalcitrant compound, poorly amenable to both CAS and MBR treatment (Zhang et al., 2008). Removals typically ranging from negligible to less than $10 \%$ in conventional MBR have been frequently reported for carbamazepine (Abegglen et al., 2009; Clara et al., 2005; Zhang et al., 2008). In this study, a rather high average removal of $68 \pm 10 \%$ was observed (Figure 3 a). The observed sulfamethoxazole removal ( $66 \pm 7 \%)$, on the other hand, was consistent with the literature data pertaining to aerobic or anoxic-aerobic MBRs (Clara et al., 2005; Nghiem et al., 2009). 
In a study conducted by Zwiener and Frimmel (2003) diclofenac was better degraded in an anoxic biofilm reactor. Enhanced removal of alkylphenolic compounds observed in a very lowloaded CAS was attributed by Clara et al. (2005) to the formation of anaerobic zones during aeration limited condition. On the other hand, Park et al. (2009) observed as high as $66 \%$ removal of carbamazepine by a constructed wetland under anoxic conditions. Maeng et al. (2011) attributed comparatively better removal of carbamazepine during river bank filtration than during artificial recharge to the anoxic environment prevailing during the former. While evidence of positive effect of anoxic regime on the removal of persistent micropollutants including carbamazepine in different forms of treatment processes are available, a comprehensive literature review revealed negligible difference in carbamazepine removal by sequential anoxic/anaerobic-aerobic MBR versus conventional aerobic MBR (Clara et al., 2005). The discrepancy of the observations in this study with the outcomes of the previous ones may stem from the difference between the 'sequential anoxic-aerobic' and 'continuous near-anoxic (DO $=0.5 \mathrm{mg} / \mathrm{L})$ ' operation modes. In an anoxicaerobic MBR oxygen transfer from the aerated compartments to the anoxic zone due to the sludge recirculation may influence the removal efficiency (Cinar et al., 2003). It is apparent that the continuous near-anoxic operation in this study favored carbamazepine removal by ensuring uninterrupted micro anoxic regions.

Although in the batch tests carbamazepine demonstrated slower degradation, during MBR operation under near-anoxic DO level $(\mathrm{DO}=0.5 \mathrm{mg} / \mathrm{L})$ the two tested compounds were removed with similar efficiency. This can be explained by the fact that accurate simulation of the conditions within the MBR cannot be expected in the batch test. Nevertheless this observation, once again, shows that owing to its inherent stability, carbamazepine degradation is very sensitive to the operating conditions.

\subsubsection{Removal under aerobic conditions $(\mathrm{DO}>2 \mathrm{mg} / \mathrm{L})$}

Sulfamethoxazole exhibited similar levels of removal even after the change of the DO level in the MBR. This is not surprising because many compounds are amenable to both aerobic and 
anaerobic biotransformation (Stasinakis et al., 2009). Of special interest was the fact that within a few days after the increase in DO level, the carbamazepine removal efficiency plummeted to almost zero. Although the removal efficiency of carbamazepine showed some improvement in the later stages (Figure 3a, beyond day 75), the removal remained below 20\% throughout further prolonged observation (data not shown).

\subsubsection{Insight into observed high removal in the studied $M B R$}

According to Knackmuss (1996), the initial electrophilic attack by oxygenases of aerobic bacteria is often a rate-limiting step for the biodegradation of many organic compounds. The presence of electron withdrawing functional groups generates an electron deficiency and thus renders the compounds less susceptible to oxidative catabolism. Apparently attack by reducing agents harbored by anaerobic microorganisms is indispensable to reduce electron deficiency of the carbamazepine molecule. Metabolite detection was beyond the scope of this study. Therefore, it could not be confirmed whether only epoxide formation or ring contraction or the cleavage of the carbamyl bond $\left(\mathrm{CONH}_{2}\right)$ (Kosjek et al., 2009) was responsible for the greater extent of disappearance of the parent compound (carbamazepine) under near-anoxic ( $\mathrm{DO}=0.5 \mathrm{mg} / \mathrm{L})$ regime.

One may wonder whether the fact that a synthetic wastewater with a high carbon to nitrogen ratio (see discussion in section 3.2), as compared to usual municipal wastewater, was utilized in this study may have had played a role in achieving high micropollutant removal. However, it is worthnoting that very low removal of carbamazepine has been reported in conventional MBRs irrespective of whether a real or synthetic wastewater was used (Bo et al., 2009; Clara et al., 2005; Laera et al., 2011). Furthermore, our previous aerobic MBR studies have demonstrated similar level of carbamazepine removal from synthetic wastewater having carbon to nitrogen rations of 7 (Hai et al., 2011) and 20 (Tadkaew et al., 2011; Tadkaew et al., 2010), respectively. Therefore, dissolved oxygen concentration, not the nature of wastewater, appears to be more important here. Notably, the maximum aerobic removal efficiency $(\sim 20 \%)$ of carbamazepine achieved in this study is similar to 
that in our previous studies (Hai et al., 2011; Tadkaew et al., 2011; Tadkaew et al., 2010) where the influent concentration of carbamazepine in the synthetic wastewater was kept at a significantly lower level $(2-5 \mu \mathrm{g} / \mathrm{L}$ as compared to $750 \mu \mathrm{g} / \mathrm{L}$ in this study). Therefore, higher influent concentration of carbamazepine as used in this study is probably not the main reason of the observed higher removal in the near-anoxic $(\mathrm{DO}=0.5 \mathrm{mg} / \mathrm{L})$ conditions. Finally, it is interesting to note that carbamazepine removal efficiency in our previous (aerobic MBR) studies (Hai et al., 2011; Tadkaew et al., 2011; Tadkaew et al., 2010) and in the current study (aerobic part) has been consistent and significantly higher than the most of the available reports (Abegglen et al., 2009; Clara et al., 2005). Considering the fact that in our laboratory, sludge from one MBR was used to inoculate the MBR in a subsequent study, it is possible that all three MBRs (the one in the current study and those described in (Hai et al., 2011; Tadkaew et al., 2011; Tadkaew et al., 2010)) harbored better carbamzepine degrading (converting) microbes, which may be furthermore effective under near-anoxic $(\mathrm{DO}=0.5 \mathrm{mg} / \mathrm{L})$ regime. Future study will need to include microbial community analysis to substantiate this interesting hypothesis.

\section{Conclusions}

The effect of dissolved oxygen (DO) concentration on the removal of selected micropollutants (sulfamethoxazole and carbamazepine) by an MBR was investigated. Remarkable changes in the removal efficiency of the known recalcitrant micropollutant carbamazepine was observed along with the transition of DO within the MBR from near-anoxic $(\mathrm{DO}=0.5 \mathrm{mg} / \mathrm{L})$ to aerobic $(\mathrm{DO}>2$ $\mathrm{mg} / \mathrm{L}$ ) conditions. On the other hand, the MBR sustained a stable removal of sulfamethoxazole irrespective of the DO level in the reactor. Batch tests conducted with the sludge collected from the MBR provided supporting evidence to the observations made in the MBR.

\section{Acknowledgements}

We acknowledge the University of Wollongong tuition fee waiver scholarship to Xueqing Li for her Master Study. The authors wish to thank Professor Kazuo Yamamoto of Environmental Science Centre, University of Tokyo, Japan for arranging the membrane module from MRE, Japan. 


\section{References}

Abegglen, C., Joss, A., McArdell, C.S., Fink, G., Schlüsener, M.P., Ternes, T.A., Siegrist, H., 2009. The fate of selected micropollutants in a single-house MBR. Water Research, 43, 2036-2046.

Bernhard, M., Müller, J., Knepper, T.P., 2006. Biodegradation of persistent polar pollutants in wastewater: Comparison of an optimised lab-scale membrane bioreactor and activated sludge treatment. Water Research, 40, 3419-3428.

Bo, L., Urase, T., Wang, X., 2009. Biodegradation of trace pharmaceutical substances in wastewater by a membrane bioreactor. Frontiers of Environmental Science \& Engineering in China, 3, 236-240.

Chu, L.-B., Zhang, X.-W., Li, X., Yang, F.-L., 2005. Simultaneous removal of organic substances and nitrogen using a membrane bioreactor seeded with anaerobic granular sludge under oxygen-limited conditions. Desalination, 172, 271-280.

Cinar, O., Deniz, T., Grady, C.P.L., 2003. Effects of Oxygen on Anoxic Biodegradation of Benzoate during Continuous Culture. Water Environment Research, 75, 434-443.

Cirja, M., Ivashechkin, P., Schäffer, A., Corvini, P., 2008. Factors affecting the removal of organic micropollutants from wastewater in conventional treatment plants (CTP) and membrane bioreactors (MBR). Reviews in Environmental Science and Biotechnology, 7, 61-78.

Clara, M., Strenn, B., Gans, O., Martinez, E., Kreuzinger, N., Kroiss, H., 2005. Removal of selected pharmaceuticals, fragrances and endocrine disrupting compounds in a membrane bioreactor and conventional wastewater treatment plants. Water Research, 39, 4797-4807.

Dipeolu, O., Gardiner, J., Stephens, G., 2005. Biocatalytic amide reduction using Clostridium sporogenes. Biotechnology Letters, 27, 1803-1807.

Eaton, A.D., Clescerl, L.S., Rice, E.W., Greenberg, A.E., 2005. Standard Methods for Examination of Water \& Wastewater $21^{\text {st }}$ ed. American Public Health Association

Hai, F.I., Tessmer, K., Nguyen, L.N., Kang, J., Price, W.E., Nghiem, L.D., 2011. Removal of micropollutants by membrane bioreactor under temperature variation. Journal of Membrane Science, (accepted-JMS-11743R1), August 2011.

Hai, F.I., Yamamoto, K., Nakajima, F., Fukushi, K., 2011. Bioaugmented membrane bioreactor (MBR) with a GAC-packed zone for high rate textile wastewater treatment. Water Research, 45, 2199-2206.

Kaiser, J.P., Feng, Y., Bollag, J.M., 1996. Microbial metabolism of pyridine, quinoline, acridine, and their derivatives under aerobic and anaerobic conditions. Microbiol. Rev., 60, 483-498.

Knackmuss, H.-J., 1996. Basic knowledge and perspectives of bioelimination of xenobiotic compounds. Journal of Biotechnology, 51, 287-295.

Kosjek, T., Andersen, H.R., Kompare, B., Ledin, A., Heath, E., 2009. Fate of Carbamazepine during Water Treatment. Environmental Science \& Technology, 43, 6256-6261.

Laera, G., Chong, M.N., Jin, B., Lopez, A., 2011. An integrated MBR-TiO2 photocatalysis process for the removal of Carbamazepine from simulated pharmaceutical industrial effluent. Bioresource Technology, 102, 7012-7015.

Li, X., Hai, F.I., Nghiem, L.D., 2011. Simultaneous activated carbon adsorption within a membrane bioreactor for an enhanced micropollutant removal. Bioresource Technology, 102, 53195324.

Maeng, S.K., Sharma, S.K., Lekkerkerker-Teunissen, K., Amy, G.L., 2011. Occurrence and fate of bulk organic matter and pharmaceutically active compounds in managed aquifer recharge: A review. Water Research, 45, 3015-3033.

Nghiem, L.D., Tadkaew, N., Sivakumar, M., 2009. Removal of trace organic contaminants by submerged membrane bioreactors. Desalination, 236, 127.

Park, N., Vanderford, B.J., Snyder, S.A., Sarp, S., Kim, S.D., Cho, J., 2009. Effective controls of micropollutants included in wastewater effluent using constructed wetlands under anoxic condition. Ecological Engineering, 35, 418-423.

Hai, F. I., Li, X., Price, W. Nghiem, L. D. (2011). Removal of carbamazepine and sulfamethoxazole by MBR under anoxic and aerobic conditions. Bioresource Technology, 102 (22), 10386-10390. 
Reungoat, J., Macova, M., Escher, B.I., Carswell, S., Mueller, J.F., Keller, J., 2010. Removal of micropollutants and reduction of biological activity in a full scale reclamation plant using ozonation and activated carbon filtration. Water Research, 44, 625-637.

Stasinakis, A.S., Kotsifa, S., Gatidou, G., Mamais, D., 2009. Diuron biodegradation in activated sludge batch reactors under aerobic and anoxic conditions. Water Research, 43, 1471-1479.

Tadkaew, N., Hai, F.I., McDonald, J.A., Khan, S.J., Nghiem, L.D., 2011. Removal of trace organics by MBR treatment: The role of molecular properties. Water Research, 45, 2439-2451.

Tadkaew, N., Sivakumar, M., Khan, S.J., McDonald, J.A., Nghiem, L.D., 2010. Effect of mixed liquor $\mathrm{pH}$ on the removal of trace organic contaminants in a membrane bioreactor. Bioresource Technology, 101, 1494-1500.

Tan, Y., Ji, G., 2010. Bacterial community structure and dominant bacteria in activated sludge from a $70{ }^{\circ} \mathrm{C}$ ultrasound-enhanced anaerobic reactor for treating carbazole-containing wastewater. Bioresource Technology, 101, 174-180.

Virkutyte, J., Varma, R.S., Jegatheesan, V., 2010. Treatment of Micropollutants in Water and Wastewater. IWA publishing, London.

Visvanathan, C., Ben Aim, R., Parameshwaran, K., 2000. Membrane separation bioreactors for wastewater treatment. Critical Reviews in Environmental Science and Technology, 30, 1-48.

Wang, C., Zeng, Y., Lou, J., Wu, P., 2007. Dynamic simulation of a WWTP operated at low dissolved oxygen condition by integrating activated sludge model and a floc model. Biochemical Engineering Journal, 33, 217-227.

Weiss, S., Reemtsma, T., 2008. Membrane bioreactors for municipal wastewater treatment - A viable option to reduce the amount of polar pollutants discharged into surface waters? Water Research, 42, 3837-3847.

Xing, C.H., Yamamoto, K., Fukushi, K., 2006. Performance of an inclined-plate membrane bioreactor at zero excess sludge discharge. Journal of Membrane Science, 275, 175-186.

Zhang, Y., Geissen, S.-U., Gal, C., 2008. Carbamazepine and diclofenac: Removal in wastewater treatment plants and occurrence in water bodies. Chemosphere, 73, 1151-1161.

Zwiener, C., Frimmel, F.H., 2003. Short-term tests with a pilot sewage plant and biofilm reactors for the biological degradation of the pharmaceutical compounds clofibric acid, ibuprofen, and diclofenac. Science of the Total Environment, 309, 201-211. 


\section{LIST OF FIGURES}

Figure 1: Removal of carbamazepine (a) and sulfamethoxazole (b) in batch anoxic/aerobic tests. Values indicate mean \pm standard deviation $(n=3)$. Initial micropollutant concentration, $\mathrm{C}_{0}=750$

$\mu \mathrm{g} / \mathrm{L}$; MLSS concentration $=10 \mathrm{~g} / \mathrm{L}$. Adsorption onto sludge and abiotic degradation were negligible.

Figure 2: Removal profile of TOC (a) and TN (b) under different DO levels.

Figure 3: Removal of carbamazepine (a) and sulfamethoxazole (b) in the course of operation of the MBR under different DO concentrations. 
- aerobic-(sludge + micropollutant + wastewater)
- anoxic- (sludge + micropollutant + wastewater)
anoxic- (sludge + micropollutant + Milli-Q water)

(a)

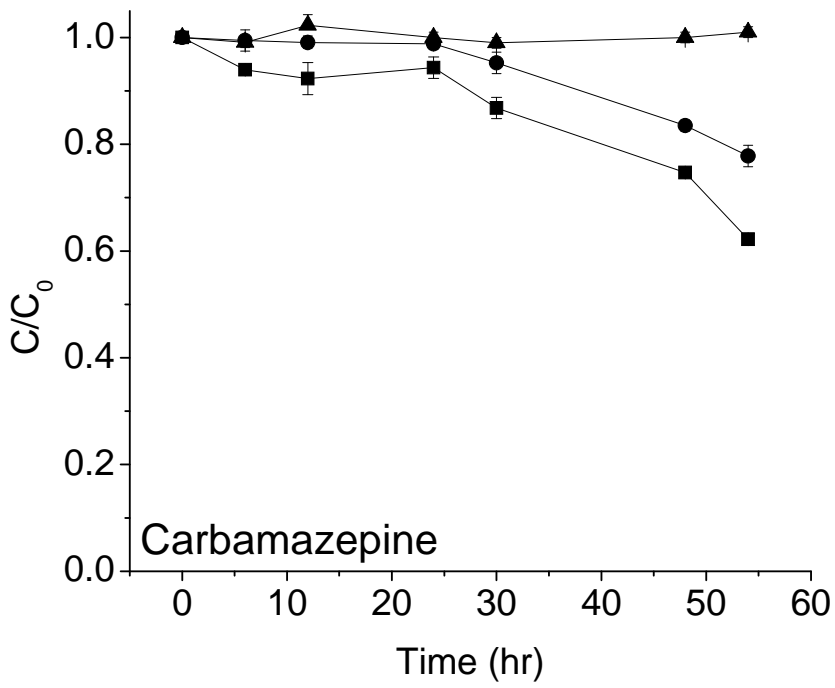

(b)

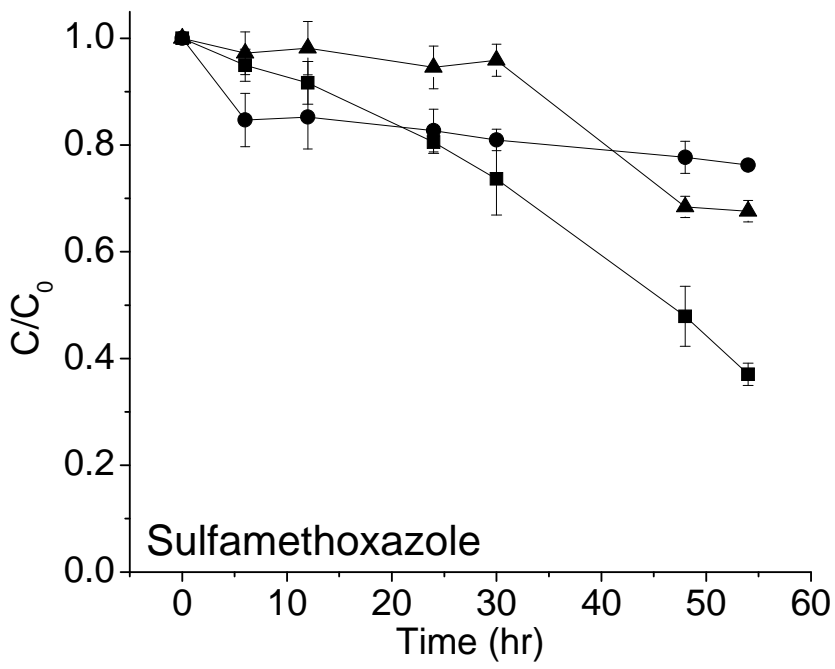

Figure 1 

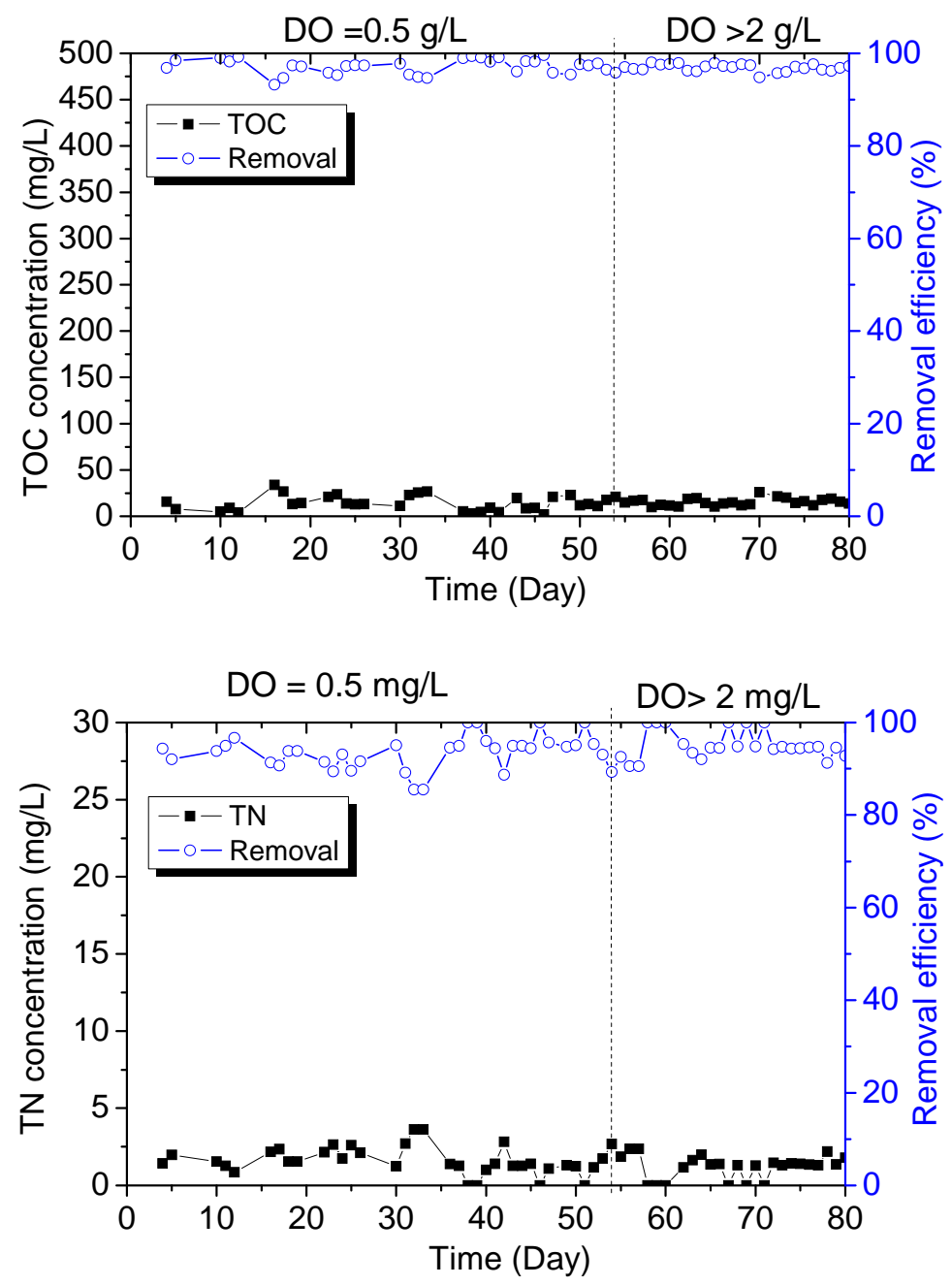

Figure 2 
(a) Carbamazepine

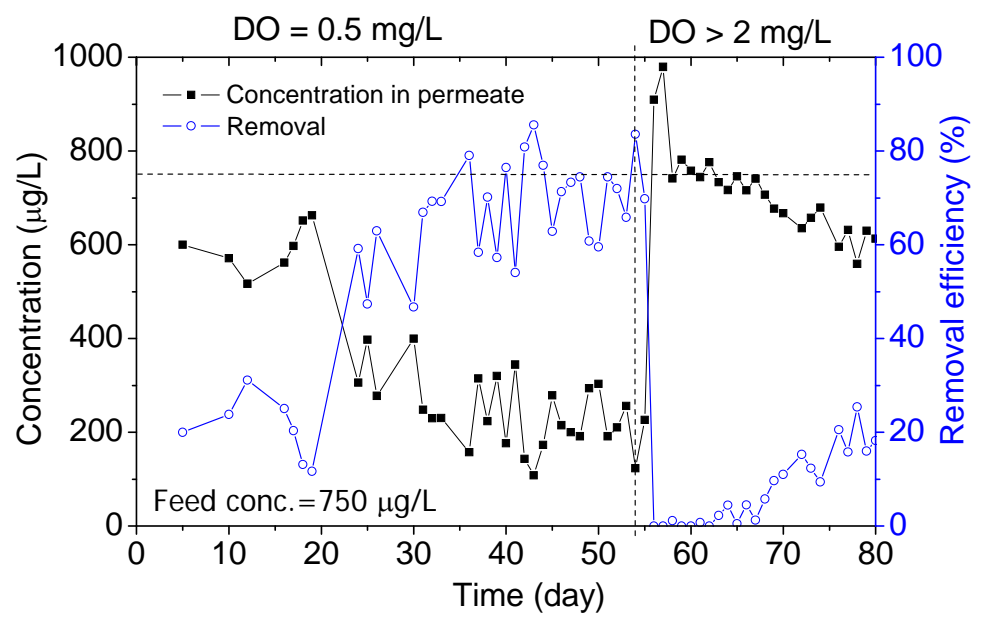

(b) Sulfamethoxazole

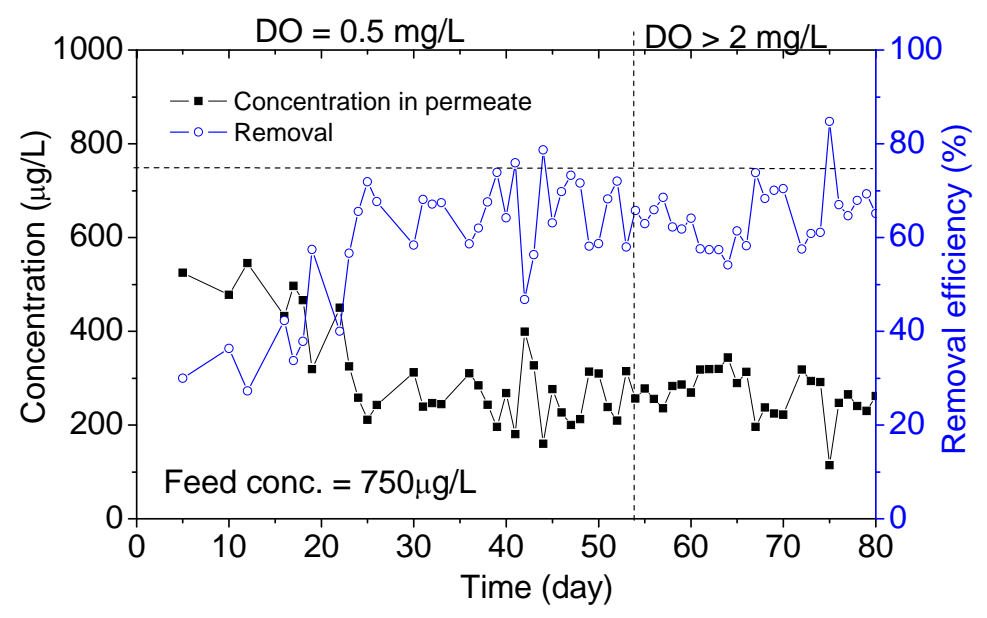

Figure 3 


\title{
Removal of carbamazepine and sulfamethoxazole by an MBR under anoxic and aerobic conditions Supplementary Data
}

\author{
Faisal I. Hai ${ }^{1}$, Xueqing $\mathrm{Li}^{1}$, William E. Price ${ }^{2}$, and Long D. Nghiem ${ }^{1, *}$ \\ ${ }^{1}$ Strategic Water Infrastructure Laboratory \\ School of Civil Mining and Environmental Engineering \\ The University of Wollongong, NSW 2522, Australia \\ ${ }^{2}$ Strategic Water Infrastructure Laboratory \\ School of Chemistry \\ The University of Wollongong, NSW 2522, Australia \\ * Corresponding author: Long Duc Nghiem, Email: longn@uow.edu.au; Ph +61 242214590
}


S1: Chemical properties of the selected micropollutants

\begin{tabular}{lcc}
\hline \multicolumn{1}{c}{ Micropollutant } & Sulfamethoxazole \\
Structure & 253.3 & 2.67 \\
Molecular weight (g/mol) & 0.9 & 0.22 \\
Log $D$ (at pH8) & 16 & $-0.49 \& 13.94$ \\
Solubility (g/L) at $25{ }^{\circ} \mathrm{C}$ and $\mathrm{pH} 8$ & $1.39 \& 5.81$ & 236.3 \\
Dissociation constant $\left(\mathrm{p} K_{a}\right)$ & &
\end{tabular}




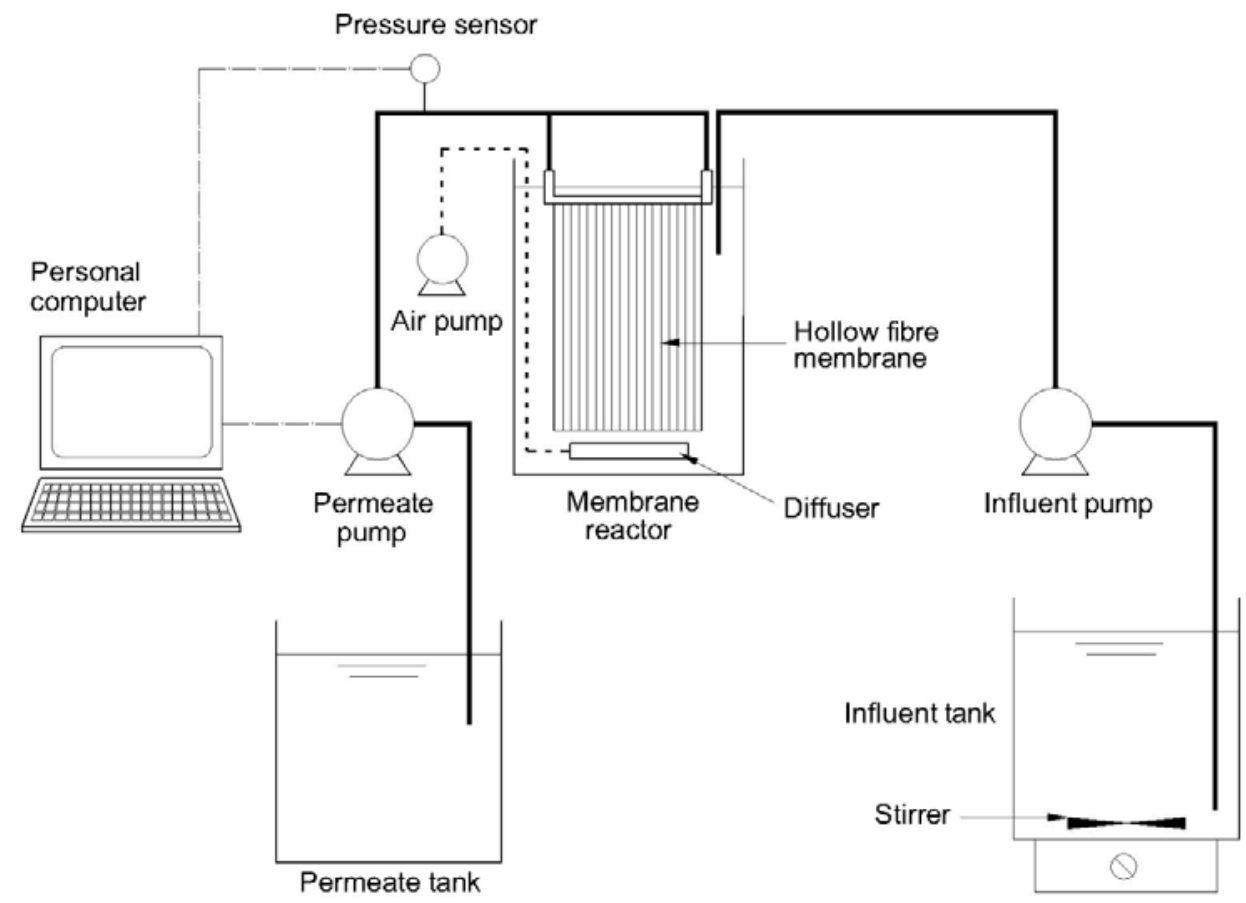

S2: Schematic of the $14 \mathrm{~L}$ laboratory-scale MBR. The system was equipped with one PVDF hollow fiber membrane module (SADF0790M mini module, Mitsubishi Rayon Engineering, Japan) which was submerged into the reactor. The membrane had a nominal pore size of 0.4 $\mu \mathrm{m}$, with a total effective membrane surface area of $0.074 \mathrm{~m}^{2}$. It was operated under a selected average flux of $0.19 \mathrm{~m}^{3} /\left(\mathrm{m}^{2}\right.$.d) on a 5 minute on/off cycle resulting in a hydraulic retention time of 24 hours. 